\title{
Representações sociais da Aids, da saúde e da doença: aportes para o Ensino de Biociências e Saúde
}

\section{Social representations of aids health and disease: contributions for biosciences and health education}

\author{
${ }^{1}$ Ana Paula Inacio Diório anapdiorio@gmail.com \\ 2 Marco Antonio Ferreira da Costa \\ ${ }^{3}$ Gustavo Clayton Alves Santana
}

\section{RESUMO}

O artigo trata-se de uma pesquisa bibliográfica descritiva, através da busca de artigos acerca das Representações Sociais da AIDS e da saúde nas bases de dados "Scientific Eletronic Library Online" (SciELO) e INDEXPSI. Os resultados apontam para a importância de estudos empíricos na área e trazem aportes para o campo de pesquisa em Ensino de Biociências e Educação em Saúde na medida que evidenciam os estudantes de ensino médio como grupo de sujeitos (re) produtores de Representações Sociais acerca da AIDS, da saúde e da doença e as instituições de ensino como campos privilegiados para a observação das representações desse grupo social.

Palavras-chave: Representações sociais. Aids. Educação em saúde.

\begin{abstract}
Article it is a descriptive literature through the search for articles about the social representations of AIDS and health in the databases "Scientific Electronic Library Online" (SciELO) and INDEXPSI. The results point to the importance of empirical research in the area and brings contributions to the field of research in Bioscience Teaching and Health Education in as evidence the high school students as a group of subjects producing social representations about AIDS, health and disease and educational institutions as key fields for the observation of representations of this social group.
\end{abstract}

Keywords: Social representations. Aids. Health education.

\footnotetext{
Fundação Oswaldo Cruz e Universidade Federal do Recôncavo da Bahia

Escola Politécnica de Saúde Joaquim Venâncio (EPSJA) e IOC/Fiocruz

Universidade Estadual do Norte Fluminense Darci Ribeiro
} 


\section{INTRODUÇÃO}

Surgida em um contexto de ruptura com o individualismo e experimentalismo e da busca por uma forma de fazer psicologia social "engajada” com as questões conjunturais, a Teoria das Representações Sociais (TRS) foi primeiro apresentada por Serge Moscovici em sua tese de doutoramento publicada em 1961, na França.

Nos últimos cinquenta anos a TRS passou de uma situação de quase anonimato para a de consolidação como um vasto campo de estudos psicossociológicos.

A rede de colaboradores que se fixou em torno das ideias de Moscovici é a principal responsável por esta consolidação, pela natureza difusa de seus objetos de pesquisa. Seus intercâmbios possibilitaram que na década de 1980 a teoria atravessasse as fronteiras europeias até chegar ao Brasil trazida por jovens pesquisadores retornados de seus estudos de doutoramento. Em solo brasileiro a TRS logo se afirma como uma alternativa muito interessante para a compreensão da dinâmica social local, principalmente nos campos de estudo da Educação e Saúde. (SANTANA, 2015).

Ferreira e Brum (2000) destacam a apropriação da teoria das Representações Sociais no campo da saúde de forma geral e citam, a utilização desse referencial teórico metodológico para o estudo da saúde do adolescente no que diz respeito á AIDS e doenças sexualmente transmissíveis, conteúdo também discutido por Tura (1997).

Já no trabalho de Joffe (2012, p. 240) a AIDS é dita “estrangeira” por conta do medo do desconhecido que motiva as pessoas a criarem Representações Sociais de novos fenômenos. Para Joffe (2012, p.240) "Os objetos sociais estranhos evocam medo, porque eles ameaçam o sentido de ordem das pessoas e sua sensação de controle sobre o mundo."

No Brasil, desde o início da epidemia, em 1980, até junho de 2014 foram registrados 757.042 casos de AIDS e só no ano de 2012 foram 39.185 (condição na qual a doença já se manifestou), ao longo de 12 anos, apesar de uma estabilização da taxa de incidência no país de forma geral e na região Sul, nas regiões Norte, Nordeste e Centro-Oeste apresentam uma tendência de crescimento linear significativo. A região Sudeste é única que apresenta tendência de queda ao longo desses anos. É importante destacar que a faixa etária, tanto de homens como de mulheres, que vem sofrendo aumento estatisticamente significativo de casos da doença esta entre jovens de 15 a 24 anos, com destaque para a faixa que vai dos 15 aos 19 anos (BRASIL, 2011; 2012; 2013;2014).

Diante dos dados que apontam para o aumento da incidência da AIDS entre jovens em idade escolar torna-se imprescindível pensar em ações de ensino e pesquisa na área da saúde. Os Parâmetros Curriculares Nacionais de Ciências Naturais sugerem que as questões de saúde sejam abordadas de forma ampla, através do eixo temático "Ser Humano e Saúde”, dentro do qual a discussão deve ser orientada pelas relações entre os problemas de saúde e fatores econômicos, políticos, históricos e sociais (BRASIL, 1998).

Nesse sentido, podemos ressaltar a contribuição dos estudos da Psicologia e das Ciências Sociais contemporâneas, o que já foi sugerido pelos Parâmetros Curriculares Nacionais (PCN) e por Diório e Costa (2014), quando destacam a dificuldade de se abordar nas escolas os eixos temáticos ditos interdisciplinares nos PCN's, com ênfase para o eixo Ser Humano e Saúde, diante de um currículo disciplinar.

A partir desse diálogo que se faz necessário entre: Representações Sociais e a pesquisa e o educação/ ensino em saúde, nosso estudo buscou averiguar o tema Representações Sociais da AIDS, em duas bases de dados: "Scientific Eletronic Library Online" (SciELO) e INDEXPSI, já que acreditamos que, além da tentativa que tem sido empregada na compreensão da doença, o diálogo com o ensino das biociências merece atenção especial pois, através dele torna-se possível pensar em estratégias voltados para o público que tem apresentado taxas crescentes de contaminação pelo HIV/AIDS nos últimos anos no Brasil, os jovens entre 15 e 24 anos, 
muitos ainda em idade escolar. Diante de tentativas fracassadas de conscientização através do proibicionismo e da cultura do medo, as Representações Sociais podem trazer alternativas de pensarmos a prevenção a partir da ótica do sujeito e não apenas do saber médico, que às vezes pode não dialogar com as representações de mundo e da própria doença que os jovens trazem consigo.

A escolha desse tema se deve a sua relevância como problema de saúde pública mundial. Excepcionalmente diante da importância da abordagem da relação saúde/doença no ensino de ciências e consequentemente da pesquisa para a área, trazer outros referenciais teóricos que permitam observar o sujeito e sua totalidade e não apenas sob o absolutismo do saber científico se mostra relevante para o debate.

Portanto, o artigo tem como objetivo discutir, a partir da inserção desse tema em periódicos científicos, a importância da Teoria das Representações Sociais (TRS) para os estudos na área do ensino das biociências e saúde, com foco na relação saúde/doença em especial a doença AIDS e suas representações.

\section{A TEORIA DAS REPRESENTAÇÕES SOCIAIS}

Assentada em um alicerce teórico e metodológico transdisciplinar a Teoria das Representações Sociais de Moscovici (1961) insere-se na fronteira da teoria social contemporânea. Definidas nas ciências sociais como ideias, ou categorias de pensamento que servem para expressar a realidade, em muitos momentos lhe explicando, em outros lhe justificando, ou até mesmo lhe questionando (MINAYO, 2012).

As representações podem romper com as características impessoais que veem o conhecimento como racionalidade pura, pois estas estando efetivamente na base de todos os sistemas de saber, de uma maneira dialógica, pois são geradas pelas inter-relações, auxiliam na sua compreensão. Esta dialogia "nos fornece a chave para entender a relação que amarra o conhecimento à pessoa, a comunidade e mundos de vida” (JOVCHELOVITCH, 2011, p. 21).

Representar, nos recorda Jovchelovitch (2011, p.33), é propriamente o ato de dar forma, de tornar presente o que está ausente, o conceito de representação "está na base da inclusão e da exclusão - quem é e quem não é representado? - no centro do nosso conhecimento sobre nós mesmos e sobre o mundo em que vivemos”.

As representações são, antes de tudo, um processo de disputa, um sistema que é construído no decurso da ação social dos sujeitos e seus grupos. "Elas implicam um trabalho simbólico que emerge das inter-relações eu, outro e objeto-mundo e, como tal, têm o poder de significar, de construir sentido, de criar realidade.” (JOVCHELOVITCH, 2011, p. 35).

Esta tarefa de familiarizar o não-familiar é cotidiana e requer dos sujeitos um exercício cognitivo constante, através do qual acionam e, utilizam-se de dois instrumentos nomeados como ancoragem e objetivação.

O primeiro consiste em sintetizar significados diferentes e externos a fim de torná-los íntimos, ou seja, transformar um conceito que pode ser ameaçador ou indizível em uma imagem familiar. Moscovici (2011, p.61) aponta que:

Este é um processo que transforma algo estranho e perturbador, que nos intriga, em nosso sistema particular de categorias e o compara com o paradigma de uma categoria que nós pensamos ser apropriada. [...]

Ancorar é, pois, classificar e dar nome a alguma coisa. 
Ao fazer isto, o indivíduo passa a ocupar-se do segundo instrumento nomeado por Moscovici, assim, objetifica o desconhecido em uma realidade por ele já institucionalizada. Conforme explica Moscovici:

Objetificação une a ideia de não familiaridade com a realidade, torna-se a verdadeira essência da realidade. [...]

Objetificar é descobrir é descobrir a qualidade icônica de uma ideia, ou ser impreciso; é reproduzir um conceito em uma imagem. Comparar é já representar, encher o que está naturalmente vazio, com substancia. (MOSCOVICI, 2011, p. 71-72).

As Representações Sociais possuem uma intima relação com a formação do saber praticado pelos sujeitos sociais e seus grupos no decurso da vida em sociedade. Como fenômenos que necessitam ser descritos e explicados. As Representações Sociais de Moscovici estão relacionadas com um modo particular de compreender e de se comunicar - um modo que cria tanto a realidade como o senso comum. É para enfatizar esta distinção que ele usa o termo "social” em vez de "coletivo" (FARR, 2012).

Diante do exposto, a Teoria das Representações Sociais se mostra relevante para a pesquisa em ensino de biociências e saúde, já que o campo também trata da subjetividade e do senso comum, principalmente, no diz respeito às doenças como a AIDS, que diante da proporção mundial que tomou, o perfil da epidemia já sofreu várias mudanças, assim como as representações delas para os sujeitos.

\section{A TEORIA DAS REPRESENTAÇÕES SOCIAIS NA RELAÇÃO SAÚDE/DOENÇA}

Muitos trabalhos já foram desenvolvidos no campo da saúde/doença (a exemplo de Jodelet (1989); Herzlich (1991); Sevalho (1993) e autores que tratam especificamente do caso da AIDS, como Joffe (1994), Spink (1992:2001), Tura (1997), Giacomozzi e Camargo (2004), Camargo (2007), entre outros), no que diz respeito à tentativa de compreensão das Representações Sociais de algumas doenças e seus desdobramentos nos campos: sócio-histórico, da psicologia e da antropologia. Agregando ainda mais conhecimento e compreensão à área médica e da saúde coletiva, no que diz respeito ao sujeito em sua totalidade e não apensas sob o absolutismo do saber científico.

Além disso, a teoria também ganha força no discurso da Educação em Saúde como argumenta Gazzinelli et al (2005) e outros autores que serão discutidos ao longo desse trabalho.

No que diz respeito às Representações Sociais da saúde e da doença, Gomes, Mendonça e Pontes (2002, p.2) acreditam que a partir desse debate as ações em saúde coletiva possam dar continuidade ao seu repensar para contemplar, visto que ele é oriundo da reflexão e das práticas sociológica e antropológica, além de contemplar as dimensões social e individual da doença, "refletidas nas permanências culturais das representações e presentes nas experiências individuais que ocorrem no processo de adoecer”.

Sendo assim, o olhar sob o corpo adoecido apenas pela ótica da medicina e da tentativa de cura e/ou amenização do sofrimento e da dor não são capazes de dar conta da complexidade do sujeito, suas experiências de vida e muito menos de suas representações sobre a doença que se abateu sobre seu estado de saúde, a qual é capaz de alterar também sua percepção de mundo e de lugar no grupo social. E por isso os esforços da pesquisa na área devem acontecer no sentido de afastar a dicotomia entre representações e práticas, corpo e mente, indivíduo e sociedade, subjetividade e objetividade. 
A fim de não reproduzir esses afastamentos Alves e Rabelo (1998, p.113) primam pelo deslocamento da doença “como fato (seja dado empírico ou signo) para o curso da doença como experiência”. Visto que as representações não são sistemas fechados, mas em constante transformação.

\section{O ENSINO DE BIOCIÊNCIAS E SAÚDE E A TEORIA DAS REPRESENTAÇÕES SOCIAIS}

A Teoria das Representações Sociais ganhou espaço e relevância na psicologia social, nas ciências sociais e nos estudos no campo da saúde, por conta de sua tentativa de aproximação entre sujeito - objeto, quando busca entender a construção da realidade que esses sujeitos fazem ao interpretar o mundo. Diante disso, e aliado à necessidade crescente das investigações em ensino de Biociências e Saúde, dialogar com os referenciais teóricos-metodológicos da Psicologia e das Ciências Sociais contemporâneas na tentativa de compreensão de questões relacionadas aos sujeitos imersos nesse contexto da educação formal e não formal se faz necessário para responder as demandas e as lacunas que ainda existem nesse campo de pesquisa.

Dentre alguns enfoques de pesquisa que consideram a TRS no âmbito do Ensino das Biociências, podem ser destacados, por exemplo: a produção de Schaffer (2007) sobre a polissemia do termo "orgânico", com alunos universitários; o trabalho de Silva \& Pitombo (2006) sobre as RS de "queima” e "combustão", com educandos do ensino básico; a investigação de Cortes Jr., Corio \& Fernandez (2009), que analisou o que alunos universitários representavam sobre "química ambiental"; o estudo de Mazzotti (1997) sobre as RS de "problema ambiental”, envolvendo professores, alunos, documentos e livros didáticos; a pesquisa de Magalhães Jr. \& Tomanik (2012) sobre educação ambiental, com alunos do ensino básico; a investigação de Hilger (2011) sobre as RS da física quântica apresentadas por estudantes do ensino médio; o trabalho de Melo, Tenório \& Accioly Jr. (2010) sobre as RS de licenciandos de Física sobre a ciência; a produção de Valença \& Falcão (2012), que descreveu as RS de professores de Biologia sobre a teoria da evolução e ainda o trabalho Fonseca e Loguercio (2013) sobre as Representações Sociais da nutrição na para a produção de um material didático de química.

Lacolla (2005), afirma que quando nos apropriamos das Representações Sociais podemos entender a maneira pela qual as concepções carregadas de sentidos se formam no pensamento dos alunos e incidem na construção dos conceitos que trabalhamos em nossas classes. Para a autora, que é professora na área de ciências naturais, tomar contato com uma teoria de origem sociológica, como é o caso das Representações Sociais, nos permite interpretar os estudos associados aos conhecimentos "ingênuos" e "espontâneos" dos alunos, suas concepções previas ou pré-concepções.

Em pesquisa realizada em 24 adolescentes da cidade de Vitoria da Conquista, na Bahia, Silva et al (2014,p.2) investigou as representações sociais sobre ser saudável desses jovens. Evidenciando a importância da teoria no deslocamento das questões ligadas à saúde dos adolescentes, as quais têm sido em sua maioria, interpretadas a luz do "paradigma biomédico, enfocando a adolescência como um fenômeno natural, universal, pautado num paradigma a-histórico e que não considera o contexto em que esse indivíduo está inserido”.

Camargo et al (2009), também encontrou na teoria das Representações Sociais um meio de compreender as representações dos adolescentes, estudantes de uma escola estadual de Florianópolis, acerca da doença AIDS e as estimações deles das representações de outros adolescentes. O resultado da pesquisa revelou uma representação da AIDS como problema social, biomédico e relacionado à intimidade, o que pode facilitar a compreensão de pesquisadores acerca do fenômeno e como ele é representado pelos jovens, que hoje, são os que apresentam um crescente quanto a contaminação pelo vírus HIV.

Nessa perspectiva, estudos que se apropriem desse aporte teórico podem ser relevantes para se pensar as políticas públicas em saúde com foco no público jovem, atendendo suas especificidades a partir da leitura de 
suas maneiras particulares de ver o mundo, as quais têm na escola um importante espaço de construção e por isso um espaço, também, de reflexão, reconstrução das representações sociais, já que é nesse ambiente que o saber científico é reificado, objetivado e ancorado na tentativa do sujeito de tornar o não- familiar em familiar, compartilhando essas construções individuais com o grupo social.

\section{CAMINHO METODOLÓGICO}

Foi realizada uma pesquisa bibliográfica descritiva, através da busca de artigos nas bases de dados "Scientific Eletronic Library Online” (SciELO) e INDEXPSI. A escolha dessas bases se deu por conta de hospedar artigos de revistas científicas relevantes e, classificadas no Qualis CAPES. Além disso, várias dessas revistas possuem um escopo na área de ensino de Biociências e Saúde, que atendem ao nosso campo de estudo. No caso da base de dados INDEXPSI, a escolha está diretamente relacionada ao fato de que, diante do objeto de estudo: as Representações Sociais da AIDS, a Psicologia Social tem dominado as produções na área, logo consideramos importante concentrar a busca numa base de dados específica da área de Psicologia.

Para o levantamento dos artigos na base de dados SciELO foram utilizadas como descritores as palavras: “representações sociais or representações sociais aids or representações sociais saúde”. Não foi delimitado um intervalo de tempo visto a necessidade de ampliar a busca, a qual poderia ser limitada pelos descritores e pela compreensão prévia dos autores de quanto é recente estabelecimento da teoria no Brasil, além de incluir o período de publicação como categoria de análise. E no caso da busca na INDEXPSI as palavras "representações sociais da AIDS”. A busca foi realizada em março de 2015. Os dados obtidos foram interpretados à luz do referencial teórico utilizado no estudo.

Foram adotadas as seguintes categorias analíticas: o período de publicação; periódicos em que foram publicados; tipos de estudo no que tange à metodologia; sujeitos das pesquisas e campos de estudo ou coleta de dados. Os artigos também foram separados de acordo com que denominados aqui de "campos” ou "temáticas".

Em relação às variáveis “tipos de estudo/metodologia”, foi necessário a aplicação de análise de conteúdo temática, seguindo procedimentos de categorização definidos por (BARDIN 2010). A justificativa para a escolha dessa técnica é dada pela dispersão e não menção clara e objetiva do conteúdo das variáveis referidas, nos estudos analisados. No caso dos “campos" ou "temáticas” foi utilizada a mesma técnica, porém, até a fase da identificação das unidades de significação temáticas ou tema, nesse caso não prosseguimos para a criação das categorias, o que seria o próximo passo da análise de conteúdo temática ou categorial baseada em Bardin.

\section{6}

\section{RESULTADOS E DISCUSSÃO}

A busca realizada no mês de março de 2015, utilizando como palavras-chave, nos três campos de busca da página do Scielo através da Library collection, com as palavras: "representações sociais or representações sociais AIDS or representações sociais saúde” e nesse caso, as palavras-chave poderiam estar em qualquer campo do registro, tais como título, resumo e palavras-chave. Foram encontrados um total de duzentos e noventa e cinco (295) artigos publicados do no período de 1993 a 2014, em trinta (30) páginas de resultados.

A segunda forma de filtrar os trabalhos foi através do título, sendo assim só foram abertos os resumos daqueles que a partir das palavras do título, como Representações Sociais da saúde e da doença e/ou da AIDS e/ ou Educação em Saúde, dialogavam com o objeto de estudo. Sendo que, o resumo foi o segundo filtro adotado, outra forma de conhecer e selecionar os trabalhos que realmente tinham a ver com o foco do estudo. A partir do segundo filtro foram selecionados 26 trabalhos e com leitura e análise do resumo o número caiu para 20. 
No segundo levantamento, também realizado em março de 2015 na base nacional de dados INDEXPSI, com as palavras-chave: "representações sociais AIDS” foram encontrados 12 artigos entre os anos de 2004 e 2011, sendo que após a leitura dos resumos todos os artigos foram selecionados para compor o corpus de análise por dialogarem com o foco principal do estudo: as Representações Sociais da AIDS.

No primeiro momento da análise buscamos elencar em quais tipos de periódicos esses trabalhos vêm sendo publicados ao longo desses anos (Tabela 1), dada a importância do campo para o ensino de Biociências e Educação em Saúde, além dos campos da Psicologia e das Ciências Sociais contemporâneas, as quais podem colaborar para pensarmos um ensino de ciências a partir de questões psicossociais que orientam as práticas dos sujeitos e dos grupos sociais nos quais estão inseridos.

Tabela 1- Distribuição dos artigos por periódicos com maior frequência de publicação

\begin{tabular}{|c|r|r|}
\hline Periódicos & Frequência & \% \\
\hline $\begin{array}{c}\text { Estudos em Pesquisa em } \\
\text { Psicologia (Impr.) }\end{array}$ & 3 & $9,3 \%$ \\
\hline Temas em Psicologia & 2 & $6,3 \%$ \\
\hline Psicologia em Estudo & 2 & $6,3 \%$ \\
\hline Psicologia, Teoria e & 2 & $6,3 \%$ \\
Prática & & \\
\hline Estudos em Psicologia (Natal) & 3 & $9,3 \%$ \\
\hline Estudos em Psicologia (Campinas) & 2 & $6,3 \%$ \\
\hline Saúde e Sociedade & 2 & $6,3 \%$ \\
\hline Caderno de Saúde Pública & 2 & $6,3 \%$ \\
\hline Psicologia e Sociedade & 2 & $6,3 \%$ \\
\hline Psico- USF & 2 & $6,3 \%$ \\
\hline Outros & 10 & $3,2 \%$ \\
\hline Total & 32 & $100 \%$ \\
\hline
\end{tabular}

Fonte: dados do estudo.

A partir dos dados apresentados (Tabela 1) podemos destacar a utilização da Teoria das Representações Sociais nos estudos na área da saúde, com ênfase para o campo da Psicologia, o que pode ser facilmente compreendido pelo fato da teoria ter nascido a partir dos estudos em Psicologia Social de Serge Moscovici na década de 1960. Desde então a teoria veio ganhando força na área e destaque em outros campos, como no caso da enfermagem, representada por trabalhos nas revistas Saúde e Sociedade, Cadernos de Saúde Pública e algumas que aparecerem na categoria "Outros”, e do ensino o qual apareceu de forma mais heterogênea dentro das revistas como um todo e mais especificamente um trabalho na Revista Educação Médica, a qual está inclusa na categoria "Outros".

No que diz respeito ao período das publicações encontradas (Tabela 2) pudemos perceber que a maioria compreende o período entre 2000-2009 (50\%) e se observarmos o intervalo de 2000 a 2015 temos o total de $97 \%$ dos artigos selecionados de acordo com o tema de estudo. Sá (2007) destaca que, apesar da primeira publicação que inaugura o campo de estudo das Representações Sociais ser datada de 1961 na França, só a partir na década de 1980 teve a consolidação do seu arcabouço teórico-conceitual básico, o que pode nos ajudar a compreender o porquê da maioria dos trabalhos estar entre os anos 2000 a 2015. Visto que, a teoria ganha força no Brasil a partir das publicações de Jodelet em 1984 e 1989 (Sá, 2007), levando certo tempo para seu amadurecimento e consolidação em solos brasileiros e sua utilização como referencial teórico-metodológico nas pesquisas, as quais 
começam no campo da saúde e veem ganhando força desde então em outras áreas, como é o caso do ensino de ciências e da latente necessidade da compreensão do fenômeno da AIDS.

É importante considerar que, esse conjunto de artigos não representa a totalidade de estudos existentes sobre Representações Sociais da AIDS, mas sim uma amostra deles, já que, as bases de dados não abrangem o total de periódicos existentes, além de conterem, em função de serem eletrônicos, apenas os artigos mais recentes (CARDOZZO et al 2007).

Tabela 2- Distribuição dos artigos por período de publicação

\begin{tabular}{|c|r|r|}
\hline Período & F & \% \\
\hline $1990-1999$ & 1 & 3,0 \\
\hline $2000-2009$ & 16 & 50,0 \\
\hline $2010-2015$ & 15 & 47,0 \\
\hline Total & 32 & 100 \\
\hline
\end{tabular}

Fonte: dados do estudo.

A separação por periódicos e por período de publicação se mostrou importante para termos um panorama geral acerca dos trabalhos que vêm sendo produzidos nas últimas décadas, tanto para o emprego da Teoria das Representações Sociais quanto para o nosso objeto específico de estudo, cujo foco é a aplicação dessa teoria no ensino de Biociências e Saúde, com destaque para o estudo da AIDS.

Para melhor compreensão da produção na área a partir dos dados coletados os artigos foram separados por campos os quais, foram obtidos a partir da elaboração de uma ficha visando à organização do corpus. Sendo assim, os trabalhos foram agrupados nos seguintes campos: 1- Representações sociais da saúde e da doença (14 artigos): Categoria 2- Representações sociais e Educação em saúde (2 artigos); Categoria 3- Representações sociais da AIDS (16 artigos): 3.1- Representações sociais da AIDS de profissionais de saúde (5 artigos), 3.2Representações sociais da AIDS , comportamento e emoções (6 artigos), 3.3- Representações sociais da AIDS conhecimento e divulgação científica (5 artigos). Sendo que, no caso do campo 3 (três) sentiu-se a necessidade do desdobramento em campos secundários como ilustrado na abaixo (Tabela 3).

A partir desses resultados pudemos observar que a maior parte dos artigos encontrados está dentro de dois campos principais: o campo 1 - Representações Sociais da saúde e da doença com 44\% (14 artigos) dos trabalhos analisados e a campo 3 - Representações Sociais da AIDS, a qual comporta 50\% (16 artigos) dos trabalhos encontrados. Sendo que, o campo 3 foi subdivida apenas para fins de análise, na tentativa de detalhar um pouco mais sobre em quais temáticas esses trabalhos têm sido produzidos a partir das Representações Sociais da AIDS. No caso do campo 2, com menor número de trabalhos, 6\% (2 artigos) mas, não menos importante, estão concentrados os artigos específicos que tratam da Educação em Saúde a partir da perspectiva das Representações Sociais, principalmente no que diz respeito a saúde e/ou a doença. 
Tabela 3- Distribuição dos artigos por campos

\begin{tabular}{|l|l|r|r|}
\hline Campos & Título & F & \% \\
\hline 1 & $\begin{array}{l}\text { Representações Sociais da saúde e da } \\
\text { doença }\end{array}$ & 14 & 44,0 \\
\hline 2 & Representações e Educação em Saúde & 2 & 6,0 \\
\hline 3 & Representações Sociais da AIDS & \multicolumn{2}{|c|}{} \\
\hline 3.1 & $\begin{array}{l}\text { Representações Sociais da AIDS de } \\
\text { profissionais de saúde }\end{array}$ & 5 & 15,6 \\
\hline 3.2 & $\begin{array}{l}\text { Representações Sociais da AIDS, } \\
\text { comportamento e emoções }\end{array}$ & 6 & 18,8 \\
\hline 3.3 & $\begin{array}{l}\text { Representações Sociais da AIDS, } \\
\text { conhecimento e divulgação científica }\end{array}$ & 5 & 15,6 \\
\hline Total & & 3 & 100 \\
\hline
\end{tabular}

Fonte: dados do estudo

\section{1 Metodologia e tipos de estudos}

No que tange a metodologia, a maior parte dos trabalhos, 96,9\% (31 artigos) dos 32 selecionados, apresentaram uma pesquisa qualitativa, enquanto 3, 1\% (1 artigo) empregou uma metodologia quanli-quantitativa. Sendo que, as técnicas de coletas de dados que mais apareceram, nesta ordem, foram os questionários abertos e fechados, entrevistas semi-estruturadas e as técnicas de evocações livre de palavras. Em muitos casos foram utilizados softwares para a análise dos dados como o ALCESTE com maior frequência, seguido do EVOC e o Tri-Deux-Mots. Sendo assim, a maior parte desse conjunto de trabalhos apresentou resultados de pesquisas empíricas.

Tais resultados corroboram com Spink (1995), quando ao debater sobre o estudo empírico das representações sociais destaca a importância da conversação para a compreensão das mesmas, visto que "as representações são resultado de um contínuo burburinho e um diálogo que é tanto interno quanto externo, e durante o qual as representações individuais ecoam ou são complementares” (MOSCOVICI, 1984, p. 950). Nesse sentido, a autora reforça ainda que para acessar esse contínuo burburinho o uso de material espontâneo é o mais adequado e que as técnicas verbais como as entrevistas abertas, os questionários e a associação livre de palavras já se mostram as mais adequadas para obtenção dos dados nos estudos das representações sociais (SPINK, 1995).

Em análise de resumos de trabalhos sobre o conhecimento acerca de HIV/AIDS realizado por Oliveira et al (2006) quanto ao tipo de estudo, pôde-se constatar um predomínio das pesquisas empíricas, correspondendo a $68 \%$ do total dos resumos analisados, seguida das análises teóricas (13\%), dados esses semelhantes aos encontrados em uma pesquisa bibliográfica acerca da investigação científica em enfermagem no Brasil no ano de 2001.

Sá (2007) apoiado nas ideias de Farr (1993) aborda que a teoria das Representações Sociais não privilegia nenhum método de pesquisa em especial, porém, destaca assim como em Abric (1994) a importância da entrevista em profundidade em qualquer estudo sobre representações sociais, ideia também privilegiada pela corrente liderada por D. Jodelet. 
As análises teóricas somaram 15,7\% (5 artigos) dos trabalhos selecionados para esse estudo, os quais apresentaram como técnica de levantamento de dados a revisão de literatura ou a pesquisa documental.

\section{2 Sujeitos e campos de estudo}

Quanto a análise dos sujeitos que apareceram nos trabalhos selecionados, assim como apresentado na Tabela 4, os profissionais de saúde ao quais compreende $28 \%$ aqui representados, principalmente por agentes de saúde, enfermeiros, médicos entre outras especialidades que atuam em hospitais e centros de saúde, e os estudantes que somam $25 \%$ do total dos grupos, foram os que apareceram mais vezes nas pesquisas empíricas , somando 53\% dos sujeitos pesquisados nos artigos selecionados para esse estudo. Enquanto pacientes, pacientes soropositivos ao HIV ou com AIDS, homens e mulheres em geral, profissionais do sexo (representados apenas por mulheres) e idosos aparecerem em dois (2) trabalhos cada, representando, cada um deles 6\% do total e somados 30\% do número de sujeitos. No caso dos profissionais de saúde a relação com o campo de estudo é bem clara, já que ao se debruçar acerca da compreensão das representações sociais da AIDS, da saúde e da doença é evidente que esses sujeitos, os quais lidam diretamente com essa realidade, sejam alvo das pesquisas empíricas, o que nos permitir pensar acerca da importância e da tentativa da compreensão das representações formuladas por esse grupo que partilha muitas características comuns: a formação, o ambiente de trabalho, às práticas do cuidado aos pacientes e entres outras as quais irão contribuir nas construções de representações da saúde e das doenças.

Oliveira et al (2006) afirma que a Teoria das Representações Sociais, em sua orientação psicossocial, tem sido cada vez mais utilizada na área de saúde, especialmente nos estudos nos quais o objetivo é ter acesso ao conhecimento social que orienta as práticas de uma dada população quanto aos problemas de saúde, indicando ter esta Teoria pertinência para a abordagem das problemáticas de interesse para os pesquisadores da área.

Ainda quanto os profissionais de saúde este resultado reafirma os apontamentos de autores como (GIAME, 1997); (RODRIGUES,2002); (GIR et al, 2002) que discutem as implicações trazidas pela epidemia para a prática profissional, em seus múltiplos aspectos, sustentando o surgimento de mudanças significativas nessas práticas, desde as relações com os pacientes até a necessidade de ter acesso ao conhecimento produzido acerca do HIV/AIDS.

Ainda a acerca da compreensão sobre esses grupos de sujeitos e as Representações Sociais, Jodelet (2001, p.32) discute que "há representações que cabem em nós como uma luva ou atravessam os indivíduos: as impostas pela ideologia dominante ou as que estão ligadas a uma condição definida pelo seio da estrutura social. ” São questões que dizem respeito a relação do caráter social da representação à inserção social dos indivíduos, ou seja, as funções que eles assumem, o lugar que ocupam e a posição social determinam os conteúdos representacionais e sua organização. E sendo assim, é através da investigação desses grupos que os pesquisadores acessam e interpretam particularidades dos contornos e identidade das representações que eles expressam, ou seja, o modo como o grupo se pensa em suas relações com os objetos que o afetam (MOSCOVICI, 2001).

As representações são, antes de tudo, um processo de disputa, um sistema que é construído no decurso da ação social dos sujeitos e seus grupos. "Elas implicam um trabalho simbólico que emerge das inter-relações eu, outro e objeto-mundo e, como tal, têm o poder de significar, de construir sentido, de criar realidade. " (JOVCHELOVITCH, 2011, p. 35).

Diante da tentativa do trabalho de trazer aportes para o ensino de biociências e saúde a partir da compreensão do estudo do campo social da AIDS, da saúde e da doença, é importante destacar como os estudantes aparecem como sujeitos de pesquisa quando falamos de Representações Sociais no campo da saúde. Representando $25 \%$ do total dos trabalhos analisados, ou seja, um quarto dessas pesquisas tinham como alvo compreender as representações de alunos e alunas jovens, em sua maioria do ensino médio, em escolas públicas, seguido das 
universidades. O que nos permiti inferir que esse grupo e campos de estudo escola/universidade são locais de atuação importante dos pesquisadores no campo das ciências humanas e sociais, sobretudo quando se trata de representações sociais, ou seja, são ambientes e grupos que possuem uma adesão coletiva e estabelecem um vínculo social que é relevante quando o foco é compreensão do pensamento e das ações da coletividade.

Tal resultado também pode ser compreendido a partir dos dados oficiais da AIDS no Brasil visto que desde o início da epidemia, em 1980, até junho de 2014 foram registrados 757.042 casos de AIDS e só no ano de 2012 foram 39.185 (condição na qual a doença já se manifestou), e ao longo de 12 anos, apesar de uma estabilização da taxa de incidência no Brasil e diminuição na região Sudeste, a taxa aumentou nas demais regiões, sobretudo entre jovens de 15 a 24 anos (BRASIL, 2011; 2013; 2014). Esse dado reforça a importância e necessidade de pesquisas com jovens em idade escolar e ainda mais dentro de um ambiente que eles passam grande parte do tempo, formulando e reformulando as representações sociais naquele grupo e espaço que diz respeito às suas construções sociais.

Sendo assim, é possível reforçar a importância dessa teoria como referencial teórico-metodológico para as pesquisas na área do ensino em biociências e saúde e no que diz respeito a importância da compreensão dos processos de comunicação e dos fenômenos relativos as formas de pensamento e ação do grupo a que se pertence, nesse caso o de estudante. E a partir dessas compreensões pensar para ações de intervenção seja para a melhoria do ambiente, como para a melhoria dos processos de ensino e aprendizagem.

Tabela 4: Categoria de sujeitos

\begin{tabular}{|c|c|c|}
\hline Sujeitos & $\mathbf{F}$ & $\%$ \\
\hline Estudantes & 8 & 25,0 \\
\hline Profissionais de saúde & 9 & 28,0 \\
\hline Pacientes & 2 & 6,0 \\
\hline $\begin{array}{l}\text { Pacientes soropositivos } \\
\text { ao HIV ou com AIDS }\end{array}$ & 2 & 6,0 \\
\hline Homens e mulheres em geral & 2 & 6,0 \\
\hline Profissionais do sexo & 2 & 6,0 \\
\hline Idosos & 2 & 6,0 \\
\hline Não se aplica* & 5 & 15,6 \\
\hline Total & 32 & 100 \\
\hline
\end{tabular}

No que se refere aos campos de estudo (Tabela 5), fica evidente que os resultados refletem e dialogam com aqueles vistos em relação aos sujeitos, quando observamos que as instituições de ensino aparecem com uma frequência de oito (8) o que reflete $25 \%$ do total de trabalhos selecionados, centros e unidades básicas de saúde cinco (5) representando 15,6\%, hospitais quatro (4) sendo 12,5\% e por fim o domicílio que apareceu apenas uma (1) vez o que representou 3\% do total dos trabalhos analisados. Assim como houve um número maior de sujeitos caracterizados como profissionais de saúde se somarmos os campos hospitais com os centros e unidades básicas de saúde, os quais corresponderam 37\% do total de trabalhos analisados, teremos a maior parte dos estudos feitos no campo relacionado à área da saúde e, consequentemente, aos profissionais que nela atuam. 
Tabela 5: Distribuição dos artigos segundo campos de estudo de pesquisa empírica

\begin{tabular}{|l|r|r|}
\hline Campo de estudo & F & \% \\
\hline nstituições de ensino & 8 & 25,0 \\
\hline Hospitais & 4 & 12,5 \\
\hline Centros e unidades básicas de saúde & 5 & 15,6 \\
\hline Domicílio & 1 & 3,0 \\
\hline Não informado & 9 & 28,0 \\
\hline Não se aplica* & 5 & 15,6 \\
\hline Total & 32 & 100 \\
\hline \multicolumn{2}{|c}{$\begin{array}{c}\text { Fonte: dados do estudo. } \\
\text { Refere-se a análise teórica. }\end{array}$} \\
\end{tabular}

\section{CONSIDERAÇÕES FINAIS}

A partir da análise dos artigos referentes a esse estudo relacionado a compreensão da AIDS, da saúde e da doença através da Teoria das Representações Sociais, pode-se observar que: a maior parte dos trabalhos encontrados na busca estão indexados nas revistas na área de Psicologia, com ênfase para a Psicologia Social: metade dos trabalhos foram publicados no período compreendido entre 2000-2009 corroborando com o tempo de chegada e amadurecimento da teoria no Brasil; a grande maioria dos estudos desenvolveu uma pesquisa empírica através de uma metodologia qualitativa baseada, principalmente, em questionários e entrevistas; os principais sujeitos dos estudos foram os profissionais de saúde seguido pelos estudantes do ensino médio e, consequentemente, os principais campos de estudo foram os ambientes de cuidados com os pacientes e as escolas públicas.

Esses resultados mostram um importante panorama, a partir dessa análise, quanto as produções na área da saúde e da educação em saúde no que diz respeito a Teoria das Representações Sociais como referencial teórico-metodológico. Visto que os resultados dialogam com a produção acerca da teoria, corroboram alguns aspectos já firmados quanto a pesquisa empírica e ainda trazem aporte para o ensino das biociências e saúde quando reafirmam a escola como um espaço (re) produtor de Representações Sociais e os sujeitos que ali coexistem como alvo de investigação afim de permitir que através da compreensão desse espaço e desse sujeito ele seja pensado, a partir, de referenciais que os humanizem e não os tornem meros objetos de pesquisa.

Nesse sentido, apesar das limitações pertinentes a esse tipo de análise, este estudo pretende contribuir para o entendimento do caminho percorrido pela Teoria das Representações Sociais na construção do conhecimento acerca da AIDS, da educação/ensino em saúde e de forma mais abrangente das questões próprias e dos significados atribuídos à saúde e a doença como produtoras de representações. 


\section{REFERÊNCIAS}

ALVES, P. C. RABELO, M. C., 1998. Repensando os estudos sobre representações e práticas em saúde/doença. In: Antropologia da Saúde: Traçando Identidades e Explorando Fronteiras (P. C. Alves \& M. C. Rabelo, org.), pp. 107-121, Rio de Janeiro: Editora Fiocruz/Relume Dumará.

BARBARÁ, A. SACHETTI, V.A.R. CREPALDI, M. A. Contribuições das representações sociais ao estudo da aids. Interação em Psicologia, 2005, 9(2), p. 331-339.

BARDIN, L. Análise de Conteúdo. $4^{\text {a }}$ Ed. Edições 70, 2010.

BRASIL. Ministério da Saúde. Departamento de DST, Aids e Hepatites Virais. Boletim Epidemiológico Aids e DST, Brasília, 2011; 2012, 2013, 2014

CARDOZZO, S. T. D. MARTINS, G. Dal F. MACARINI, S.M. VIEIRA, M, L. Perspectivas no estudo do brincar: um levantamento bibliográfico. Aletheia, n.26, p.122-136, jul./dez. 2007.

CAMARGO, B.V. Barbará, A. Bertoldo, R.B. Concepção pragmática e científica dos adolescentes sobre a Aids. Psicologia em Estudo. V. 12, n. 2, p. 277-284, 2007.

p. 710-723, 2009.

Representações sociais da AIDS e alteridade. Estudos e pesquisas em Psicologia, Ano 9, N.3,

DIÓRIO, A.P; COSTA, M.A.F. Parâmetros Curriculares de Ciências Naturais: a questão da interdisciplinaridade e da transversalidade no Ensino de Ciências. Anais do IV Encontro Nacional de Ensino de Ciências da Saúde e do Ambiente, 2014. Disponível em:http://www.ivenecienciassubmissao.uff.br/ index.php/ivenecienciassubmissao

FARR, R. Theory and method in the study of social representations. In: BREAKWELL, G.M; CANTER, D.V (Orgs.). Empirical approaches to social representations. Oxford: Clarendon Press, p. 15-38, 1993.

FARR,R. Representações Sociais: a teoria e sua história. In: GUARESCHI, P. JOVCHELOVITCH, S (Orgs). Textos em Representações Sociais. Petrópolis: Vozes, 2012.

FERREIRA, N.S.A. As pesquisas denominadas “Estado da Arte”. Educação \& Sociedade, 79, 257-272, 2002.

FERREIRA, S.R.S. BRUM, J.L.R. As representações sociais e suas contribuições no campo da saúde. Revista Gaúcha de Enfermagem, v.20, n.esp., p. 5-14, 2000.

GAZELli, M.F. GAZELli, A. REIS, D. C dos. PENNA,C. M..M. Educação em saúde: conhecimentos, representações sociais e experiências da doença. Caderno de Saúde Pública, 21(1):200-206,2005.

GIACOMOZZI, A.I. CAMARGO, B. V. Eu confio no meu marido: estudo da representação social de mulheres com parceiro fixo sobre prevenção da AIDS. Psicologia: Teoria e Prática, 6(1): 31-44, 2004.

GIAMI, A. Enfermeiras frente à AIDS: representações e condutas, permanência e mudanças. Canoas (RS): ULBRA; 1997.

GIR, E. SILVA, A.M. COSTA, F.P.P. HAYASHIDA M. Alterações na prática profissional de enfermeiros de um hospital de ensino do interior paulista, em conseqüência ao surgimento do HIV/AIDS. Rev. Gaúch. Enferm. 2000 Jul; 21 (2): 37-54.

GOMES, R.; MENDONÇA, E. A. \& PONTES, M. L. Cad. Saúde Pública, Rio de Janeiro, 18(5):1207-1214, 2002 
HERZLICH, C. A Problemática da Representação Social e sua Utilidade no Campo da Doença. Revista de Saúde Coletiva. Vol. 1.1, n. 2, Rio de Janeiro, 1991.

JODELET, D. Folies et Représentations Sociales. Paris: PUF, 1989.

JODELET, D. Representações sociais: um domínio em expansão. In: JODELET, D. Representaçõe sociais. Rio de Janeiro: Eduerj, 2001.

JOFFE, H. "Eu não”, “o meu grupo não”: representações sociais transculturais da Aids. In: GUARESCHI, P.; JOVCHELOVITCH , S. Textos em Representações Sociais. Petrópolis: Vozes, 2012. p. 239-261.

JOVCHELOVITCH, S. Os contextos do saber: representações, comunidade e cultura. $2^{\text {a }}$ ed. Petrópolis: Vozes, 2011.

LACOLLA, L. Representaciones sociales: una manera de entender las ideas de nuestros alumnos. Revista ieRed: Revista Electrónica de la Red de Investigación Educativa . Vol.1, No.3, 2005.

MINAYO, M. C. D. S. O Conceito de Representações Sociais dentro da Sociologia Clássica. In: GUARESCHI, P.; JOVCHELOVITCH , S. Textos em Representações Sociais. Petrópolis: Vozes, 2012. p. 73-92.

MOSCOVICI, S. Representações Sociais: investigações em psicologia social. Petrópolis: Vozes, 2011.

OLIVEIRA, D.C. COSTA, T.L. GOMES, A.M.T. ACIOLI, S. FORMOZO, G.A. HERINGER, A. GIAMI, A. Análise da produção de conhecimento sobre o hiv/aids em resumos de artigos em periódicos brasileiros de enfermagem, no período de 1980 a 2005. Texto Contexto Enfermagem, 2006; 15(4): 654-662.

OLIVEIRA, D.C. A enfermagem e as necessidades humanas básicas: o saber/fazer a partir das representações sociais [tese]. Rio de Janeiro (RJ): UERJ/Faculdade de Enfermagem; 2001.

RODRIGUES, R.M. BAGNATO, M.H.S. Pesquisa em enfermagem no Brasil: problematizando a produção de conhecimentos. Rev. Bras. Enferm. No 56 (6): 646-50, 2003.

SEVALHO, G. A Historical Approach to Social Representations of Health and Disease. Cad.Saúde Públ., Rio de Janeiro, 9 (3): 349-363, 1993.

SILVA, A. C. S. SALES, Z.N. MOREIRA, R.M. BOERY, E.M. TEIXEIRA, J.R.B. BOERY, R.N.S DE O. Representações sociais sobre ser saudável de adolescentes escolares. Adolesc. Saude, Rio de Janeiro, v. 11, n. 1, p. 24-31, 2014.

SÁ, C.P. As representações sociais na história recente e na atualidade da Psicologia Social. In JACÓ-VILLELA, A.M. FERREIRA, A.A.L. PORTUGAL (Orgs.). História da psicologia: rumos e percusos. Rio de Janeiro: NAUED, 2007.

SPINK, M.J.P. et al. A construção da Aids-notícia. Caderno de Saúde Pública, 17(4):851-862, 2001.

SPINK, M.J.P O estudo empírico das Representações Sociais. In SPINK, M.J.P (Orgs.) O conhecimento no cotidiano: as representações sociais na perspectiva da psicologia social. São Paulo: Brasiliense, 1995.

SPINK, M.J.P. A construção social do saber sobre saúde e doença: uma perspectiva psicossocial. Saúde e Sociedade, 1 (2), 125-139, 1992.

TURA, L.F.R. Os jovens e a prevenção da Aids no Rio de Janeiro. Rio de Janeiro: Faculdade de Medicina da Universidade Federal do Rio de Janeiro (Tese de doutorado), 1997. 